\title{
The Application of Energy Tower Heat Pump Technology in Air Conditioning Engineering
}

\author{
Dong YANG ${ }^{1, a}$ and Hui-chao QI ${ }^{2, b, *}$ \\ ${ }^{1}$ Key Laboratory of Renewable Energy Utilization Technologies in Buildings, Ministry of Education,Jinan250101, China \\ ${ }^{2}$ School of Thermal Energy Engineering, Shandong Jianzhu University, Jinan 250101,China \\ a497128514@qq.com, b2284170728@qq.com
}

\begin{abstract}
Explain the development character of energy tower heat pump technology, introduce the working principle of tower of energy of the system and the way of operation and management, analysis and comparison of energy tower and the different methods of cooling towers and other cooling, heating . Comparing with other air conditioning mode, through the analysis, that energy tower can realize the comprehensive utilization of resources and save energy and reduce consumption. The new technology can be used as an alternative of air conditioning equipment to achieve cooling ,heating and hot water supplying in the areas to south of the Yangtze River in China. Effectively solve the problem of air source heat pump in winter frost in winter, and ground source heat pump is limited used in the southern region .
\end{abstract}

Keywords-component; energy tower; heat pump; energy conservation and emissions reduction

\section{THE RESEARCH BACKGROUND AND SIGNIFICANCE}

Of energy tower heat pump technology originated in Japan in the $80 \mathrm{~s}$ last century, is heated or heating towers. In order to meet the energy requirements in the field of air conditioning, and constantly optimize the perfect, this is a dual purpose of the cooling tower, is the comprehensive utilization of the advantages of the cooling tower and air source heat pump. Energy tower heat pump technology is the technology to realize heating, cooling, and provide hot water. In winter, energy tower uses carrier medium below freezing point, low grade heat energy efficient extraction of wet air below freezing point. Input a small amount of high-grade energy through energy tower heat pump unit, achieve low grade heat energy to high grade, realize heating. In the summer because of the special design, energy tower have the effect of high efficiency cooling tower, will carry out their refrigeration heat into the atmosphere.

\section{A. Applicable Climate and Scope}

Energy tower heat pump air conditioning system is suitable for the rainy season, the air humidity is big, damp cold region. As we all know, traditional air source heat pump frost is serious when heating in winter. Especially in the rainy weather, air humidity, cold and wet areas, the defrosting problem is serious, and the efficiency is low. The energy tower will overcome this interference, no frost problems in the damp and cold air humidity conditions, so it can be stable and efficient extraction of the heat of the wet bulb below the freezing point. Relatively stable than aircooled heat exchanger performance, the performance coefficient of COP can be changed in the range of 3 to 3.5 for the whole winter.

\section{B. Energy Saving Potential}

Special energy tower structure design, the low grade energy in the air is extracted by the anti freezing liquid circulation in winter, efficient use of huge latent energy, eliminating the need for auxiliary heating boiler that is unsanitary and pollute the environment. Conventional refrigeration is used in summer. The heat transfer area of the carrier is high energy efficiency. In addition to cooling and heating, it can provide hot water, three with a machine. Improve the utilization rate of equipment, reduce the initial investment, energy saving and environmental protection.

\section{Research Meaning}

The research of energy tower system can understand the working principle of the energy tower system, determine its scope of use and applicable conditions, at the same time to provide a feasible solution for further optimization performance. The successful application of energy tower technology can provide a better basis for energy conservation and emissions reduction enterprise, is a powerful support in response to environmental policies at home and abroad.

\section{ENERGY TOWER HEAT PUMP SYSTEM}

Energy tower heat pump system is composed of four parts: energy tower heat exchange system, energy tower heat pump unit, pipeline switching device and building system.

In summer, the energy tower system provides a stable source of cooling for the host by evaporative cooling. The energy tower is equivalent to the sense of the cooling tower. The circulating water which is higher than the air wet bulb temperature is evenly sprinkled on the concave and convex wave plate of the cooling tower. A layer of water film is formed on the hydrophilic filler. The air is circulated through the surface of the multilayer concave and convex wave plate filler, and the heat transfer between the air and the water film is hot and latent heat. The heat of the cooling water is absorbed by the latent heat exchange, and the temperature of the cooling water is reduced.

In the winter, the energy tower system can effectively extract the sensible heat and latent heat of the humid air under 0 degrees Celsius, and can provide a stable heat source 
under the condition of -15 . The spray on the anti freezing solution which is lower than the temperature of the wet bulb is evenly sprayed on the concave and convex wave plate, and the liquid film is formed. The air is circulated through the surface of the multilayer concave and convex wave plate filler, and the heat transfer between the sensible heat and latent heat of the liquid membrane is carried out. Anti freeze fluid absorbs the heat of water in the air and exchange heat with the cooling medium.

Energy tower system for the summer to provide $7^{\circ} \mathrm{C}$ supply water and $12^{\circ} \mathrm{C}$ backwater and for the winter to provide $45^{\circ} \mathrm{C}$ supply water and $40^{\circ} \mathrm{C}$ backwater. At the same time to provide hot water and $55^{\circ} \mathrm{C}$ water for bathing, sauna or dedicated $60^{\circ} \mathrm{C}-95^{\circ} \mathrm{C}$ high temperature water .

\section{A. Energy Tower Heat Pump Unit}

Energy tower heat pump units using a double condenser full heat recovery technology, with air conditioning condenser and hot water using condenser two sets of system, 4 different operation conditions are realized by using the valve switching. (that is, the separate refrigeration conditions, separate heating conditions, separate system of living hot water conditions, refrigeration and hot water conditions at the same time system.

In essence, energy tower heat pump unit is an advanced form of air source heat pump unit, but more than air source heat pump refrigerant the two heat exchanger with the air side. From another perspective, energy tower heat pump units from the water (ground) source heat pump. Compared with conventional water source heat pump, energy tower heat pump unit increased oil cooler. The water inlet pipe of the condenser is connected with a water pipe to the oil cooler, and the oil cooler outlet is connected with the condenser outlet pipe. When the compressor discharge temperature is higher, the electromagnetic valve is closed, the oil flows through the oil cooler and then enters the compressor. Energy tower heat pump operating conditions shown in Figure 1. Cooling in summer and at the same time making living hot water, heating in winter.

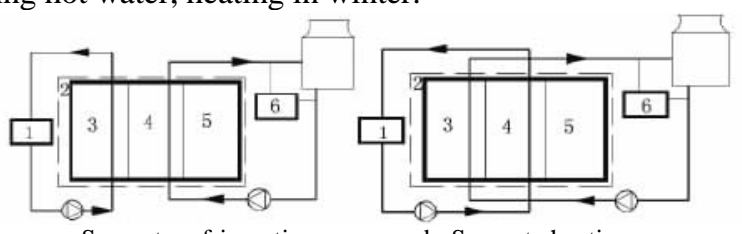

a. Separate refrigeration process b. Separate heating process

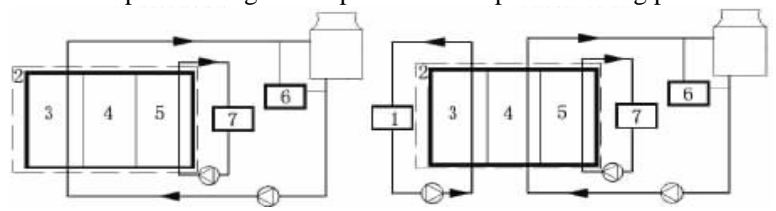

c. Separate living hot water flow d. Refrigeration for making living hot water flow at the same time

1 air conditioning terminal 2 heat pump unit 3The evaporator 4 Condenser for air conditioner 5 Condenser for domestic hot water 6Automatic dosing device 7 Heat storage water tank

Figure 1. Schematic diagram of 4 operating conditions of energy tower heat pump system

\section{B. Energy Tower Heat Exchange System}

The energy tower heat exchange system includes energy tower, solution pump, solution concentration control device, solution storage device and auxiliary pipeline system.

Energy tower is divided into open type cooling tower and closed type cooling tower, in order to enhance the heat transfer process of the tower body, the energy tower usually adopts the reverse flow of mechanical ventilation.

\section{1) Open type cooling tower}

In the open type cooling tower, In order to increase the contact area of the liquid in air and not frozen, to extend the time of heat exchanger, enhance heat transfer effect, will increase the packing in the tower.

\section{a) Operation flow of open energy tower}

As shown in figure 2.When the energy tower heat pump system work stability, the winter condition is an example. Firstly, energy tower, the air of low temperature and high humidity from the bottom of the open energy tower into the tower. The heat and mass exchange is carried out by the nonfreezing liquid film which is under the action of the upper to lower than the dew point temperature, which is fully distributed in the filler. Because the temperature of the liquid film of the low temperature is lower than the dew point temperature of the air, the air entering the energy tower is low in temperature, but has high moisture content, and a large amount of latent heat is contained in the water. Therefore, when the air and non-freezing liquid contact to reduce the temperature of heat release, water vapor condensation into water droplets and release a lot of latent heat, the non-freezing liquid absorb the heat causes the temperature to rise. In addition, between the energy tower and plate heat exchanger. The non-freezing liquid absorb low grade heat of the air in the energy tower, the non-freezing liquid temperature is improved and then flow to the corrosion of plate heat exchanger. Non-freezing fluid transfer energy to secondary refrigerant of release heat in the evaporator cooling agent, and its temperature is reduced, and then through the non-freezing fluid circulation pump into the energy of tower body again. Finally, the secondary refrigerant of obtain heat from the board for corrosion enters the condenser and release the low grade energy , and then through the heat pump units will be low-grade energy to upgrade to a relatively high grade energy for air conditioning heating in winter.

\section{b) System features of open energy tower}

For open energy tower, the biggest characteristic is that the low temperature non-freezing liquid in the tower body and the wet air that the temperature is relatively high and contains a lot of moisture to carry on the direct and the full contact,which has a good heat transfer effect .In addition, the traditional refrigerant such as ethylene glycol solution of high cost, easy to volatilize, has certain toxicity to the animal. In open energy tower heat exchange system, only between the refrigerant and the heat pump unit in anti-corrosive board for small flow circulation in the room, which will not only reduce the cost of investment and later maintenance, but also reduce the impact of ethylene glycol on human health. 


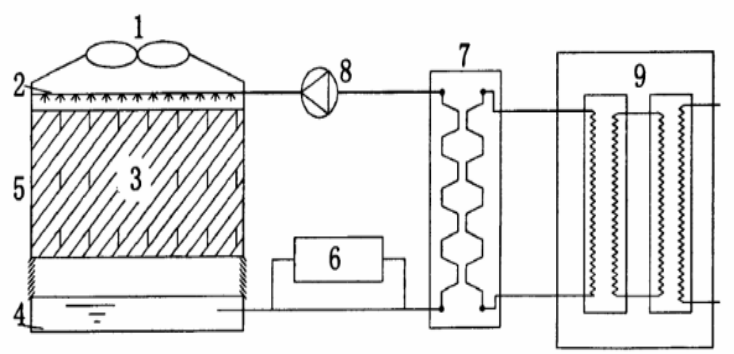

1 fan 2 water distributor 3 packing 4 defrosting pan 5 The tower body 6 Non-freezing liquid concentration control device 7 Anti-corrosion board 8 Non-freezing fluid circulation pump 9 Heat pump host

Figure 2 Open upstream mechanical ventilation packing energy tower system diagram

But the non-freezing liquid and heat pump system using anti-corrosion board for indirect connection. Heat transport process with loss and increase anti - corrosion board for investment. Because the liquid is directly contacted with the air, the temperature of the solution is easily affected by the outside, so it is necessary to start the solution concentration device.

\section{2) Closed type cooling tower}

a) Operation flow of closed energy tower

Analysis of energy transfer in winter condition .In the tower body, the air of low temperature and high humidity from the bottom around the energy tower into the tower and flow away from the top of the tower. The flow of the tower coil is a low temperature refrigerant, it is released from the evaporator of heat pump unit. The refrigerant temperature is lower than the dew point temperature of air. At the same time, the water distribution device at the top of the tower body is evenly sprayed on the surface of the heat exchange coil. This forms the antifreeze liquid flow from top to bottom, the air flow from bottom, and antifreeze liquid and air exchange heat and mass, which result in the sensible heat in the air is transferred to the non-freezing liquid, at the same time the latent heat of condensation of water vapor in the air is absorbed by the non-freezing liquid, and then the frozen liquid absorption of heat transfer for the secondary refrigerant flow in hot coil. Then non-freezing fluid fall into water pans, the water pump transport it to the water distributor for the next cycle.

Closed energy tower, secondary refrigerant is not in direct contact with air and indirect absorb heat. After the temperature has been improved, into the heat pump unit, to carry out the cycle.

b) System features of closed energy tower

Compared with the closed energy tower and closed cooling tower routine, the biggest feature is not frost. The non-freezing fluid below air dew point temperature by water distributor from the top down evenly sprayed. It absorb in the heat exchanger surface of the water, to avoid the problem of frost formation, also saves the defrosting of the electric energy consumption. Furthermore, closed type cooling tower don't need corrosion heat exchanger. This reduces the heat loss of the heat exchanger, there is no need to change in maintenance costs.In addition, because the refrigerant has been in a closed pipeline, to avoid leakage of refrigerant.

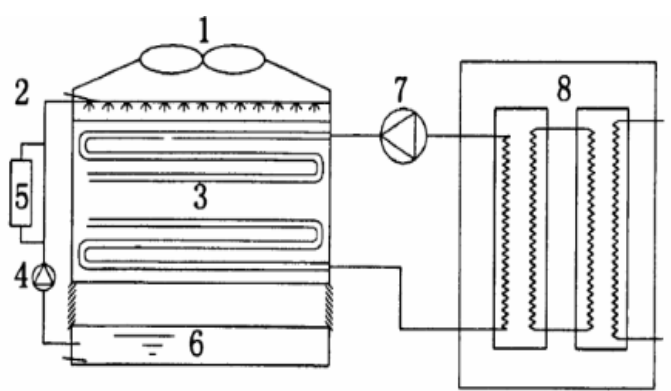

1 fan 2 water distributor 3 Heat exchange coil 4 Non-freezing fluid circulation pump 5 Non-freezing liquid concentration control device 6 defrosting pan 7 Secondary refrigerant circulating pump 8 Heat pump host

Figure 3 Closed upstream mechanical ventilation packing energy tower system diagram

However, heat pump refrigerant through the heat exchanger pipe flow in the energy tower. Because the energy tower and heat pump unit is usually far away, so it caused the loss of heat in the transmission process. In addition, refrigerant (glycol) the price is higher, the investment cost is higher, may be volatile leakage during transportation, will cause harm.

\section{The Tower of Heat and Mass Exchange Principle}

Because the composition of the liquid is mainly water, the heat and mass exchange between the liquid and the air can be considered as the heat and mass exchange between the water and the air. Sprayed non freezing liquid in the energy tower, it temperature is lower than the dew point of the air. There is a difference in air temperature, so there will be a significant heat exchange, which will occur in the state of the water change, there is a latent heat exchange. Sensible heat exchange and latent heat exchange are the energy of the whole heat exchange.

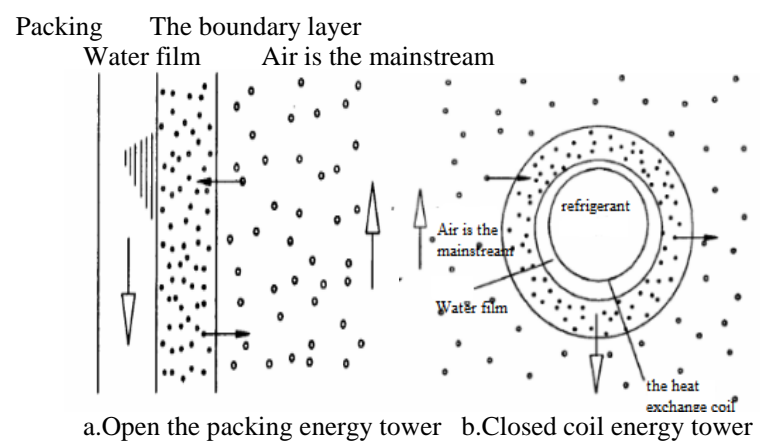

Figure 4 Direct contact heat and mass transfer process between air and water 


\section{COMPARISON WITH COMMONLY USED AIR CONDITIONING SYSTEMS OF ENERGY TOWER HEAT PUMP SYSTEM}

TABLE 1 FORM CONTRAST

\begin{tabular}{|c|c|c|}
\hline \multicolumn{2}{|c|}{$\begin{array}{l}\text { The air conditioning } \\
\text { system }\end{array}$} & System characteristics \\
\hline \multicolumn{2}{|c|}{$\begin{array}{l}\text { Single cooler water } \\
\text { machine+The boiler }\end{array}$} & $\begin{array}{l}\text { The comprehensive energy efficiency is } \\
\text { low, simple design and construction, large } \\
\text { energy consumption, secondary pollution }\end{array}$ \\
\hline \multicolumn{2}{|c|}{ Air-cooled heat pump } & $\begin{array}{l}\text { Comprehensive energy efficiency is } \\
\text { lower, design, construction simple, no } \\
\text { boiler, energy consumption, in the winter } \\
\text { frost difficulties and can't boot the hidden } \\
\text { danger, the heating effect is poor, auxiliary } \\
\text { heating equipment }\end{array}$ \\
\hline \multirow[t]{3}{*}{$\begin{array}{l}\text { Ground } \\
\text { source heat } \\
\text { pump }\end{array}$} & $\begin{array}{c}\text { Vertical } \\
\text { buried tube }\end{array}$ & $\begin{array}{l}\text { Totally enclosed system, stable and } \\
\text { reliable, high COP, no pollution, high } \\
\text { investment and relatively large, need } \\
\text { professional design and experienced } \\
\text { construction, field buried pipe }\end{array}$ \\
\hline & $\begin{array}{l}\text { Under } \\
\text { ground } \\
\text { drilling }\end{array}$ & $\begin{array}{c}\text { high COP, the system is stable and } \\
\text { reliable, no pollution,requirements of } \\
\text { underground water temperature, water } \\
\text { volume }\end{array}$ \\
\hline & $\begin{array}{r}\text { Lake } \\
\text { water heat }\end{array}$ & $\begin{array}{c}\text { high COP, the system is stable and } \\
\text { reliable, no pollution,need a lake, river and } \\
\text { other good heat transfer conditions }\end{array}$ \\
\hline \multicolumn{2}{|c|}{$\begin{array}{l}\text { energy tower heat } \\
\text { pump }\end{array}$} & $\begin{array}{c}\text { Patent technology (suitable for the } \\
\text { middle and lower reaches of the Yangtze } \\
\text { river area),high COP and without auxiliary } \\
\text { heating heat pump, suitable for large } \\
\text { projects }\end{array}$ \\
\hline
\end{tabular}

\section{CONCLUSION}

Energy tower system has obvious difference with cooling towers, cooling tower and energy tower of structure is different, and the cooling tower's capacity to absorb low grade heat source is not enough. When the tower is converted into a cooling tower, tower efficiency is more than $50 \%$ higher than the cooling tower.
The energy tower heat pump system is suitable for the south of the Yangtze River, and the outdoor wet bulb temperature is higher than $-9{ }^{\circ} \mathrm{C}$, it is mainly used to satisfy the refrigeration, heating and domestic water demand of hotels, guesthouses and community buildings.Energy tower energy-saving effect is obvious, in the new building and the existing building has a certain energy-saving advantages. In the water source heat pump, ground source heat pump to use a limited place, the energy tower heat pump has a certain energy-saving advantages.

\section{ACKNOWLEDGEMENTS}

This work was supported by Ministry of Housing Science and technology projects in 2016(K12016071) and Natural Science Foundation of Shandong Province (2016ZRB01880)

\section{REFERENCES}

[1] Song Yingqian, Ma Hongquan, Long Weiding. The application of energy tower heat pump technology in air conditioning engineering and analysis [J]. Heating Ventilating \& Air Conditioning, 2011, 41 (4) : 20-23.

[2] Qi Fei , Zhang Xinli, Yu Jiang, etc. Energy Tower Heat Pump System and Its Application[J]. Intelligent Building \& City Information,2011 (7) : 83-85.

[3] Zhang Chen,Yang Honghai,Liu Qiuke,etc. Open the heat source tower in the analysis of application of heat pump system [J]. Journal of energy research and information, 2010, 26 (1) : 52-56.

[4] Liu Qiuke ,Wang Wuying. Heat source heat pump can low thermal regeneration tower technology application in the south of China $[\mathrm{J}]$. Construction Science and Technology, 2008 (15) : 124-125.

[5] Wang Xudong. Analysis of energy tower heat pump system and its comprehensive application [J]. China New Technologies and Products, 2014 (11) : 112-112.

[6] Zhang Jianhui, Liu Zhen, Xiong Zhonghua. Air source heat pump units: CN, CN 203067261 U [P]. 2013.

[7] Zhang Chen, Yang Honghai, Liu Qiuke, etc. Enclosed is used as the heat source tower air conditioning heat and cold source analysis [J]. Building Energy \& Environment, 2009, 28 (6) : 71-73. 